\title{
PROTECCIÓN SOCIAL Y POLÍTICAS DE PROMOCIÓN DEL TRABAJO ASOCIATIVO Y AUTOGESTIONADO EN LA ARGENTINA (2003-2013): EL PROGRAMA ARGENTINA TRABAJA SOCIAL PROTECTION AND POLICIES OF PROMOTION OF ASSOCIATED AND SELF-MANAGED WORK IN ARGENTINA (2003-2013): THE ARGENTINA TRABAJA PROGRAMME
}

\author{
Denise Kasparian \\ Instituto de Investigaciones Gino Germani, Facultad de Ciencias \\ Sociales, Universidad de Buenos Aires, Argentina \\ denise.kasparian@gmail.com
}

\begin{abstract}
Resumen
El objetivo del artículo es examinar los modos de protección social que instaura el Programa Argentina Trabaja, de modo de aproximarnos al análisis de la calidad del trabajo generado por el Programa. A través de la revisión bibliográfica y el análisis documental, se identificaron aspectos positivos al respecto: la inscripción de los beneficiarios en el monotributo social, la percepción de la Asignación Universal por Hijo, y la conformación de cooperativas como modalidad de trabajo. La masividad del Programa y el monto del ingreso son elementos que potencian los cambios sociales que se proponen desde el diseño. No obstante, existen tensiones y limitaciones: las escasas posibilidades de diseñar e implementar autónomamente las actividades de las cooperativas; la percepción individual de los ingresos, y que los mismos no alcancen el salario mínimo vital y móvil, ni sean actualizados según los estándares del empleo asalariado formal; y los límites que aún acarrea el monotributo social en cuanto al efectivo uso de los beneficios que contempla. Se concluye que el Programa aporta mejorías para los trabajadores provenientes de la informalidad, mientras que, en comparación con la protección social anclada en el empleo formal asalariado, evidencia carencias.
\end{abstract}

Palabras clave: trabajo asociativo y autogestionado; sistemas de protección social; política social; integración social; contra-reforma. 


\begin{abstract}
The objective of the paper is to examine the modes of social protection established by the Argentina Trabaja Programme, so as to analyse the quality of the work generated by the Programme. Through bibliographic review and document analysis, positive elements in this regard were identified: the registration of the beneficiaries in the social monotribute, the perception of the universal child income, and the formation of cooperatives as a mode of work. The massiveness of the Programme and the amount of the income are elements that enhance the social changes proposed in the design. However, there are tensions and limitations: the limited possibilities of designing and implementing the activities of the cooperatives autonomously; the individual perception of the incomes, and that they neither reach the minimum wage, nor are updated by the standards of formal salaried employment; and the limits that still carries the social monotribute regarding the effective use of the benefits that provides. It is concluded that the Programme improves the conditions of workers coming from informality, while, in comparison with social protection provided to formal salaried workers, it shows deficiencies.
\end{abstract}

Keywords: associated and self-managed work; social protection systems; social policy; social integration; counter-reformation.

Extended abstract: The objective of this paper is to examine the modes of social protection established by the Argentina Trabaja Programme, so as to analyse the quality of the work generated by the Programme. Our main questions are: How have social policy and social protection evolved in Argentina? At what point in the field of social policy do the policies of promotion of associative and self-managed work and, more specifically, the Argentina Trabaja Programme arise? What kind of social protection does the Programme introduce? What are the differences with the social protection system anchored in formal salaried employment? To what extent does the Programme contribute to the promotion of "quality" work? Through bibliographic review and document analysis, especially of official documents, we analyse the Programme in terms of its innovations and limitations regarding social protection and social policy, aiming to make an assessment of its contribution to the construction of "quality" work.

By the mid-twentieth century in Argentina, although in much lower degrees than those achieved in core countries, the ability to protect of the social security had reached high levels. From the seventies, in line with the transformation of the Welfare State in core countries, rising levels of unemployment began to be observed in Argentinean labor market. Added to this, the classical form of employment with protection and social security began to mutate into ways of employment with different forms of precarization. The dismantling of social protection systems associated with formal salaried employment began. This process was deepened during the nineties, as a financial valuation model with neoliberal hegemony was consolidated. 
Through the workfare scheme, this neoliberal logic was imposed in policies of intervention upon unemployment from 1996. This scheme of social policy conceives the poor as an abnormal social sector which needs to be socialized in the "culture of work". In this sense, beneficiaries of conditional cash transfer programmes must develop compensations in work.

In late 2001 and early 2002, the socially and economically regressive model introduced in Argentina from the mid-seventies, and with more power in the nineties, imploded through a generalized crisis, altering the entire social order. After the crisis, a cycle of political-institutional recomposition and economic growth was inaugurated. From 2003 employment levels and wages were recovered, increasing the proportion of registered workers, so that a reduction in levels of precariousness was observed. Within this cycle, social protection was reconfigured and expanded, to the point that this period has been conceptualized as a "counter-reform" in the field of social policy (Danani and Hintze, 2011). One of the main objectives of social protection during these years has been to develop -and enlarge- coverage of vulnerable sectors affected by decades of unemployment and precariousness. In this context, we are particularly interested in the centrality the "quality" work acquired in public policy since 2003.

Along these lines, associative and self-managed work has been promoted through various public policies as a way of getting access to a "quality" work, that is to say, a work -though different from the formal salaried employmentwhich allows the access to social protection. In this article we focus specifically on the Programa de Ingreso Social con Trabajo, better known as Argentina Trabaja Programme (PAT). Launched in 2009, its objective has been to include vulnerable social sectors and achieve genuine work alternatives through the promotion of cooperatives. The centrality of this Programme resides in the fact that it replicates in a national scale similar programs that had been promoting associated and self-managed work in a smaller scale since 2003.

The analysis of Argentina Trabaja Programme allowed us identify innovations and positive aspects regarding social protection: the registration of beneficiaries in the social monotribute, the perception of the universal child income, and the formation of cooperatives as a mode of work. The massiveness of the Programme and the amount of the income are elements that enhance the social changes proposed in the design. However, tensions and limitations arising mainly from the hybrid nature of the Programme were observed, as it has some elements that tend to the social inclusion of vulnerable social sectors and others that maintain characteristics of assistance. In this second sense we observed: the limited possibilities of autonomously designing and implementing the activities of the cooperatives, the individual perception of the incomes, and that they neither reach the minimum wage, nor are updated by the standards of formal salaried employment, and the limits that still carries the social monotribute regarding the effective use of the benefits that provides. It is concluded that the Programme improves the conditions of workers coming from informality, while, in comparison with social protection provided to formal salaried workers, it shows deficiencies. 
In short, social protection established by the Programme generates an improvement of living conditions in social sectors coming from informality. Through alternative forms of work, such as the participation in cooperatives, provides greater levels of social protection, contributing to building "quality" work. However, compared to social protection destined to formal salaried work, it evidences its weaknesses and the long way ahead towards ensuring "quality" work for all members of society.

\section{INTRODUCCIÓN}

Los sistemas de protección social, a través de diversos dispositivos y a lo largo de la historia moderna y contemporánea, han sido construidos persiguiendo el objetivo del bienestar social. Con el ascenso del capitalismo industrial y los Estados de Bienestar ${ }^{1}$, las intervenciones del Estado tendientes a la producción de las condiciones de vida y a la protección de la sociedad frente a los riesgos, cristalizaron principalmente en sistemas de seguridad social basados en el tipo de inserción de las personas en el mercado de trabajo.

Hacia mediados del siglo XX en la Argentina, aunque en grados muy inferiores a los alcanzados en los países centrales, la capacidad de protección de la seguridad social había alcanzado altos niveles. En sintonía con las transformaciones del Estado de Bienestar en los países centrales, a partir de la década del setenta, comenzaron a observarse niveles crecientes de desempleo en el mercado de trabajo argentino. Sumado a esto, la forma clásica de empleo con protección y seguridad social comenzó a mutar hacia modos de empleo con distintas formas de precarización. De este modo, se iniciaba el desmantelamiento de los sistemas de protección social asociados al trabajo asalariado. Este proceso se profundizó durante la década del noventa, momento en el cual se consolidó un modelo de acumulación marcado por el régimen de convertibilidad de la moneda ${ }^{2}$, las privatizaciones, y la liberalización, que impactó fuertemente

${ }^{1}$ El Estado de bienestar o Estado social proporciona un sistema de pensiones, de educación y de prestaciones sanitarias, en el marco de una sociedad salarial que establece una gestión regulada de las desigualdades, cuyo horizonte es la reducción de las mismas (Castel, 2012).

${ }^{2}$ El régimen de convertibilidad de la moneda, popularmente conocido como "el 1 a l", establecía un tipo de cambio fijo de la moneda argentina, en el cual un peso equivalía a un dólar estadounidense. La convertibilidad fue instaurada en marzo de 1991 a través de la Ley 23.928 sancionada por el Congreso Nacional durante el Gobierno de Carlos Saúl Menem y se extendió hasta el año 2002. Cabe mencionar que los gobiernos de Menem se caracterizaron por su alineación con los valores, las ideas y las políticas postuladas por el neoliberalismo (privatización de empresas estatales, reforma del Estado, apertura comercial, desregulación económica y financiera, etc.). El objetivo principal del régimen de convertibilidad fue detener el proceso inflacionario, es decir, estabilizar el nivel de precios. En un 
en la dinámica del mercado de trabajo y en la distribución del ingreso (Damill y Frenkel, 2006).

Hacia finales de 2001 y comienzos de 2002, el modelo social, económico y político de carácter regresivo instaurado en la Argentina a partir de mediados de la década del setenta, y con mayor potencia en la década del noventa, hizo implosión a través de una inusitada crisis generalizada, alterando la totalidad del ordenamiento social. Luego de dicha crisis, se inauguró un ciclo de recomposición político-institucional y de crecimiento económico. En el año 2003, asumió el gobierno del Estado nacional una alianza social progresista con eje en el peronismo que produjo importantes rupturas políticas, económicas y sociales con los gobiernos de la década anterior ${ }^{3}$. A partir de aquí, se recuperaron los niveles de empleo y los salarios, incrementándose la proporción de trabajadores registrados, de modo que se observó una reducción de los niveles de precariedad laboral ${ }^{4}$ (Groisman, 2010). Dentro de este ciclo, destacan los modos en que se reconfiguró y amplió la protección social, siendo tal la resignificación operada sobre la misma que esta etapa ha sido conceptualizada como de contra-reforma -respecto al período de hegemonía neoliberal5 ${ }^{5}$ en el campo de la política social (Danani y Hintze, 2011). Uno de los objetivos principales de la protección social en este marco de contra-reforma se centró en desarrollar -y ampliar- mecanismos de cobertura de los sectores vulne-

primer momento, resultó exitoso en cuanto a la estabilización de precios y motorizó un proceso de crecimiento económico. No obstante, a medida que disminuía la capacidad ociosa se evidenciaba la imposibilidad de la convertibilidad de desarrollar un proceso económico sustentable en términos de distribución del ingreso y de crecimiento económico (Basualdo, 2003). La crisis generalizada de los años 2001 y 2002 puso de manifiesto con una extrema crudeza los perjuicios y consecuencias negativas de aquel régimen, en términos no sólo económicos, sino también políticos, sociales y culturales.

${ }^{3}$ La presidencia del Estado nacional es asumida por Néstor Kirchner (2003-2007) y posteriormente por Cristina Fernández (2007-2011). Actualmente, Cristina Fernández se encuentra en ejercicio de su segundo mandato presidencial, el cual finaliza en diciembre de 2015 .

${ }^{4}$ Cabe aclarar que la problemática de la informalidad laboral -factor nodal de la precarización en la Argentina- con sus efectos regresivos en términos de protección social, persistió como un límite de difícil reversión del modelo actual. En el año 2010 el 45\% de los ocupados urbanos estaba conformado por trabajadores asalariados no registrados y por cuenta propia no profesionales, es decir, aún permanecían en condiciones de informalidad (Groisman, 2011), mientras que en el segundo trimestre de 2013 el porcentaje de asalariados no registrados en la seguridad social continuaba siendo elevado: ascendía al 34,4\% (Encuesta Permanente de Hogares, Instituto Nacional de Estadística y Censos).

${ }^{5}$ El período de hegemonía neoliberal refiere a las dos presidencias de Carlos Menem, las cuales se desarrollaron entre los años 1989 y 1999, y a la presidencia de Fernando De la Rúa que comenzó en el año 1999 y finalizó antes de la culminación de su mandato en el contexto de la crisis generalizada que se desató en diciembre de 2001 y precipitó su renuncia. 
rables afectados por décadas de desempleo y precarización laboral. En este contexto, nos interesa particularmente la centralidad que adquirió el trabajo "de calidad" en las políticas públicas del Estado nacional a partir del año 2003, afirmándose que aquél brinda dignidad, socializa, incluye, y provee los medios de vida; colocándose consecuentemente en él las expectativas de inclusión y de seguridad de la reproducción de las personas (Grassi, 2012).

En esta línea, el trabajo asociativo y autogestionado ha sido fomentado a través de diversas políticas públicas en tanto vía de acceso a un trabajo "de calidad", es decir, a un trabajo que, aunque distinto del empleo formal asalariado, permita acceder a la protección social. En el presente artículo nos enfocaremos específicamente en el Programa de Ingreso Social con Trabajo, más conocido como Programa Argentina Trabaja (PAT). Lanzado el 15 de agosto de 2009, a través de la Resolución N³182/09 del Ministerio de Desarrollo Social de la Nación, se planteó como objetivo avanzar hacia la inclusión de los sectores sociales en situación de mayor vulnerabilidad y lograr genuinas alternativas de trabajo a través de la promoción de cooperativas de trabajo para la ejecución de obras de infraestructura (Memoria detallada del estado de la Nación, 2013). La centralidad de este Programa radica en que replicó a nivel nacional programas de características similares en cuanto al fomento del trabajo asociativo y autogestionado que se venían desarrollando a menor escala en la Argentina desde el año $2003^{6}$.

El objetivo del presente artículo es examinar los modos de protección social que establece el Programa Argentina Trabaja, de modo de aproximarnos al análisis de la calidad del trabajo generado por el Programa. Para esto, en primer lugar, revisaremos los principales conceptos concernientes a la política social y realizaremos un breve racconto de la política social argentina reciente. Luego, describiremos de manera detallada los lineamientos del Programa Argentina Trabaja y las singularidades de su implementación en territorio. De este modo, identificaremos las innovaciones, las continuidades y los límites que introduce en el contexto de la política social argentina, realizando un balance respecto

${ }^{6}$ Algunos planes y programas que antecedieron -y algunos de los cuales continúan funcionando- al Programa Argentina Trabaja en la creación de cooperativas de trabajo desde el Estado nacional fueron el Plan Nacional de Desarrollo Local y Economía Social "Manos a la Obra", que funcionó bajo la órbita del Ministerio de Desarrollo Social de la Nación y fue puesto en marcha en agosto de 2003; el subprograma Mejoramiento del Hábitat Urbano, el Programa Federal de Mejoramiento de Viviendas "Mejor Vivir", y la construcción de Centros Integradores Comunitarios, los cuales fueron ejecutados bajo el paraguas institucional del Programa Federal de Emergencia Habitacional concertado en el 2003 por el Ministerio de Planificación, Inversión Pública y Servicios de la Nación y el Ministerio de Desarrollo Social de la Nación; y el Plan Agua + Trabajo lanzado en el 2004, entre otros. 
a los modos de protección social que instaura. A lo largo del presente escrito nos aproximaremos a las siguientes preguntas: ¿Cómo han evolucionado la política social y la protección social en la Argentina reciente? ¿En qué momento del campo de la política social surgen las políticas de promoción del trabajo asociativo y autogestionado, y más específicamente, el PAT? ¿Qué tipo de protección social instaura? ¿En qué se diferencia o aparta del sistema de protección social anclado en el empleo formal asalariado? ¿En qué medida contribuye o, por el contrario, limita la promoción del trabajo "de calidad"?

\section{LA POLÍTICA SOCIAL: PRECISIONES CONCEPTUALES Y SU DESARROLLO EN LA ARGENTINA}

Danani (2009) propone definir el concepto de política social, en primera instancia, a partir de su objeto directo de intervención. En este sentido, afirma que la política social refiere al conjunto de intervenciones sociales del Estado que producen las condiciones de vida y de reproducción de la vida, tanto social como de los sujetos. No obstante, advierte la autora, esta definición es incompleta. Mientras que las intervenciones sociales pueden rastrearse a través de la larga historia de la sociedad humana, la política social nació al calor de la modernidad capitalista. Es allí donde la relación capital-trabajo (la forma mercancía de la fuerza de trabajo) se constituye en la relación fundamental, revistiendo centralidad en la conformación de las condiciones de vida de los sujetos y de las sociedades. En el ámbito laboral se fundan las condiciones de vida, pues allí se obtienen los medios para satisfacer -claro que en diversos grados- las necesidades individuales y sociales. Desde la perspectiva de los sujetos, las protecciones representan necesidades de reproducción de la vida; y con respecto a la sociedad, son exigencia de la acumulación en términos de la reproducción de la fuerza de trabajo (Danani y Hintze, 2011). En este sentido, la seguridad social, considerada derecho de ciudadanía a la protección, está conformada por las políticas e instituciones que se abocan a la atención de las contingencias sociales mediante la distribución de las consecuencias económicas del padecimiento de los riesgos (Hintze, 2013). La mercantilización del trabajo humano que inaugura la modernidad enfrenta a la sociedad a la desprotección; y la política social se orienta a proteger a la sociedad del riesgo que implica esta mercantilización, es decir, la dependencia de los individuos de los ingresos laborales.

Para esto, opera diversos procesos de desmercantilización, definidos como procesos a través de los cuales se prestan servicios en calidad de derechos, de modo que éstos se sustraen del mercado y las personas pueden garantizarse la vida sin depender exclusivamente del mercado (Esping-Andersen, 1993). Dos 
tipos de procesos de desmercantilización pueden identificarse: de las necesidades y de las personas (Danani, 2009). En el caso de los primeros, ciertos bienes y servicios que satisfacen determinadas necesidades son desmercantilizados. En el segundo caso, y tomando en consideración la indicación de Polanyi (2007) respecto al estatus de mercancía ficticia de la fuerza de trabajo, el carácter mercantil del trabajo de las personas disminuye a través de políticas que transfieren ingresos sin contraprestación de trabajo, o que intervienen en los mecanismos de oferta y demanda del mercado de trabajo.

En definitiva, retomando la propuesta de definir a partir del objeto de intervención, la política social es, entonces, el conjunto de intervenciones sociales del Estado que regulan indirectamente la relación fundamental en la sociedad capitalista, operando sobre la distribución secundaria del ingreso (Danani, 2009) ${ }^{7}$. Por el contrario, la política laboral regula directamente la forma mercancía de la fuerza de trabajo e interviene en la distribución primaria del ingreso. Concretamente, regula las condiciones de venta y de uso de la fuerza de trabajo, siendo un ejemplo de este tipo de política el establecimiento de un salario mínimo y un seguro de desempleo.

El sistema más difundido de protección social, el Estado de Bienestar ${ }^{8}$, se constituyó sobre dos pilares fundamentales: el pleno empleo y la solidaridad sistémica (Tokman, 2006). La solidaridad sistémica se activaba a través de dos instituciones fundamentales. Por un lado, una legislación laboral que reconocía la no igualdad de las partes involucradas y, por tanto, estaba destinada a

${ }^{7}$ Desde otra perspectiva, la política social es una intervención de la sociedad sobre los modos en que individuos y grupos se integran a la sociedad; éstos actúan con un doble patrón. Por un lado, las intervenciones en el centro que refuerzan los procesos de integración, y por el otro, las intervenciones en los márgenes con el objeto de compensar a aquellos grupos que no pueden acceder a los mecanismos de integración centrales. En la Argentina, durante la década del noventa primó el segundo patrón, asistencializando la política social, a la vez que se desarrollaba la flexibilización y precarización del empleo (Soldano y Andrenacci, 2006).

${ }^{8} \mathrm{El}$ autor agrupa los sistemas de protección social en tres regímenes de bienestar que, aunque comparten el hecho de apoyar la demanda e indemnizar los riesgos sociales, han desarrollado distintos dispositivos de protección social: el Liberal-residual, centrado en el mercado; el Conservador-corporatista que tiene como pilar a la familia y/o la iglesia y; el Socialdemocrata-universalista que tiene como centralidad al Estado. El mercado, la familia y/o iglesia, y el Estado, respectivamente, son las instituciones de cada régimen encargadas de garantizar el bienestar. El primero se desarrolló principalmente en los países anglosajones y buscó la cobertura social de los pobres a través de políticas sociales dirigidas exclusivamente a dicho sector. El segundo definió como su objetivo el mantenimiento de los ingresos de los trabajadores y procuró garantizarlo a través de seguros sociales financiados por cotizaciones sociales. Finalmente, el régimen social-demócrata se orientó a la consecución de la igualdad entre los ciudadanos desarrollando políticas universales y servicios sociales gratuitos (Esping-Andersen y Palier, 2011). 
la protección de los trabajadores (estabilidad, condiciones de trabajo, remuneraciones, negociación colectiva). Por el otro, un sistema de seguridad social en un sentido amplio que brindaba protección frente a los riesgos (vejez, accidentes e incapacidades, desempleo) mediante seguros sobre base contributiva para quienes podían aportar, complementándose con asistencia social para quienes no tenían la capacidad suficiente para participar financieramente. Dicho diseño originario de Europa se trasladó, en diferentes medidas, a los países de América Latina. Tres diferencias estructurales marcaron este traslado de la cobertura universal al ámbito latinoamericano: la ubicación en el proceso de transición demográfica, el grado de modernidad de la estructura de ocupación y la capacidad fiscal para responder a las necesidades de protección. Como resultado, se arribó a una cobertura insuficiente de los riesgos: hacia 1980, momento en el cual los países europeos gozaban de una cobertura universal en pensiones, en América Latina sólo el 41\% de los asalariados tenía cobertura y cerca de la mitad de los países no alcanzaba al 25\% de cobertura (Tokman, 2006). No obstante, hacia mediados de la década del ochenta existía un grupo de países conformado por Argentina, Brasil, Chile y Uruguay que registraban una mayor cobertura de seguridad social, superior al 67\% (Tokman, 2006).

En este sentido, hacia mediados del siglo XX en la Argentina se había logrado una cierta amplitud de la protección social, basada en el reconocimiento de derechos, principalmente, del trabajador asalariado formal. A partir de allí, el sistema de seguridad social se estructuró en función del lugar que se ocupaba dentro del mercado de trabajo, y por lo tanto, los niveles de protección al alcance de las personas se hallaron supeditados a ese vínculo laboral-y su formalidad-. En tal sentido, en este modelo de política social que se orientaba a la integración de la sociedad, los atributos del trabajo de cada individuo se constituían en los elementos centrales que definían su tipo de inserción en la sociedad, en detrimento de otros sostenes de la identidad como la familia o la comunidad de pertenencia (Castel, 1995). Castel (2012) afirma que el trabajo era el epicentro de la cuestión social, dado que una relación laboral estable proporcionaba la base para la integración a la sociedad 9 .

A pesar de que los aportes de Esping-Andersen respecto a los regímenes de bienestar fueron pensados desde y para la realidad de países en los cuales

\footnotetext{
${ }^{9}$ La integración social puede ser definida como el proceso conflictivo e inacabado a través del cual una sociedad se mantiene cohesionada y construye un "nosotros" que lo distingue de otros colectivos (Hopp, 2013; Soldano y Andrenacci, 2006). En este contexto, las desiguales formas de reconocimiento institucional de los diversos grupos y prácticas sociales dan cuenta de los alcances y límites del acceso a derechos y de la calidad de los lazos sociales construidos por los distintos grupos y en el marco de diversas prácticas.
} 
la sociedad industrial se desarrolló en su máxima expresión, los modelos de política social que se derivan de los mismos permiten abordar, en cierta medi$\mathrm{da}$, el caso argentino. En este sentido, el "modelo conservador-corporativista" describe, en parte, la configuración de la política social argentina hasta la década del setenta: baja desmercantilización de la fuerza de trabajo, dado que las protecciones y beneficios solían estar atados a la participación en el mercado de trabajo; y formas y grados variables de desmercantilización de las necesidades y sus satisfactores (Danani, 2009).

De la mano de las sucesivas dictaduras militares, y con una mayor profundización en la década del noventa, este esquema se vio debilitado, siendo reemplazado progresivamente por espacios de valorización, remercantilizando la fuerza de trabajo y las necesidades (Danani y Hintze, 2011). El neoliberalismo emergió y con él la ponderación de atributos tales como la autosuficiencia, la autonomía, la flexibilidad, y la productividad, frente a los cuales la protección social se presentaba como signo de debilidad o ineficiencia (Sennett, 2012; Kessler y Merklen, 2013; Merklen, 2013). Las protecciones y la cobertura de los riesgos sociales comenzaron a ser cuestionadas y verse debilitadas (Castel, 2013). Los criterios de eficiencia, rentabilidad y riesgo pasaron de imperar en el ámbito empresarial a impregnar múltiples dimensiones de la vida social (Sennet, 2003); y las políticas comenzaron a diseñarse bajo el imperativo de la reducción del gasto estatal y el déficit fiscal. Se actualizó la cuestión en torno a las posibles interacciones entre el mercado laboral y los sistemas de protección social -o entre las decisiones de participación en el mercado de trabajo y las transferencias de ingresos-, sosteniendo la hipótesis de que una mayor flexibilidad en los mercados laborales, junto con sistemas de protección menos generosos, permitirían realizar un ajuste más veloz en el ascendente desempleo. El argumento central sostenía que los excesivos beneficios que otorgaban los estados de bienestar a los desocupados u ocupados de bajos ingresos conspiraban contra la retención de las personas en la actividad económica (Groisman, Bossert y Sconfienza, 2011). En este sentido, El Estado comenzó a reducir sus responsabilidades mediante la limitación de las garantías fijas o permanentes y las sustituyó por actos de ayuda más temporales (Sennett, 2003). Una profunda reorientación de la forma de la relación entre el Estado y la sociedad tuvo lugar, redefiniendo las causas, los efectos y las posibles soluciones de los problemas sociales (Merklen, 2013).

La metamorfosis de la cuestión social se puso de manifiesto con los crecientes índices de desocupación, subocupación e informalidad, dejando en el olvido la sociedad del -casi- pleno empleo e inaugurando una etapa de creciente y persistente precarización laboral (Castel, 1995). La noción de preca- 
riedad fue definida en el sentido de la desvinculación del salario de la protección social provocada por una serie de fenómenos de desestructuración de los mercados de trabajo; y en la Argentina esto se dio principalmente a través de la no registración de los asalariados en la seguridad social por parte de sus empleadores (Palomino, 2008). En el plano subjetivo, el trabajo se vio disminuido en su potencial identitario (Castel, 1995.). La capacidad integradora del trabajo fue debilitada por estos cambios, hasta el punto de generalizarse el diagnóstico de la "pérdida de la centralidad del trabajo" (Castel, 2012). A pesar de dichas transformaciones, el trabajo continuó revistiendo centralidad en la cultura de los trabajadores en la Argentina. Algunos estudios dieron cuenta de la vigencia de esta cultura, incluso cuando el desempleo y la precarización alcanzaron sus valores máximos (e.g. Férnandez Álvarez, 2007; Danani y Grassi, 2009; Maneiro, 2012).

En cuanto a la política social, la reorientación en la relación entre Estado y sociedad se evidenció en políticas de individuación. Éstas se caracterizaron por abandonar el objetivo moderno de integración y socialización a través de regulaciones y protecciones orientadas a la construcción de un orden social, cuyos sujetos eran "derechohabientes"; y pasar a intervenir sobre el otro "con el propósito de transformar a cada sujeto en un individuo en acuerdo con los valores de la autonomía, la responsabilidad, la activación y el seguro de sí mismo ante los riesgos"(Merklen, 2013: 73), de modo de prepararlo para la competencia que implica la vida social.

Por su parte, Castel conceptualiza este cambio en el terreno de la política social como el pasaje desde políticas de integración hacia políticas de inserción (1995). Se asiste al progresivo abandono de los mecanismos estables de la integración social, es decir, políticas universales, homogeneizantes y generadoras de grandes equilibrios (acceso universal a servicios sociales considerados derechos de modo de tender a la igualdad de posiciones y de oportunidades); y al desarrollo de políticas y estrategias específicas con una lógica de discriminación positiva cuyo objetivo es focalizar en poblaciones y zonas particulares. La distinción entre políticas universales y focalizadas no surge de la mano de las políticas de inserción. Por el contrario, ésta ya existe en la relación clásica de complementariedad entre seguro social y ayuda social. Mientras el primero realiza una socialización generalizada de los riesgos al cubrir a los asalariados y sus familias, la segunda destina recursos subsidiarios a aquellos cuya reproducción no está asegurada por el trabajo, por recursos insuficientes o invalidez. A diferencia de la ayuda social, las políticas de inserción se manejan en una zona incierta en la que aumenta la desocupación y la precarización, 
no dependiendo las situaciones de la nueva población destinataria de las políticas de factores individuales de anormalidad o inadaptación.

La crisis social, económica y política del año 2001 en la Argentina marcó un punto de inflexión, fuertemente cargado de críticas hacia dicho esquema acompañado de revisiones, transformaciones, marchas y contramarchas respecto a la protección social. A partir del año 2003, revertida la crisis y en un proceso de fuerte recuperación económica y social, se pasó de los programas de transferencia de emergencia a las estrategias de protección social (Vuotto, 2013). Los primeros años del siglo XXI fueron testigo de la revitalización de las políticas públicas con un enfoque de derechos. Por un lado, Palomino (2008) observa la emergencia de un nuevo régimen de empleo con protección social a partir de 2005, que se diferencia del anterior régimen de precarización laboral instalado a partir de la década del noventa con el modelo de la convertibilidad. Por el otro, a partir del 2003, en términos de Danani y Hintze (2011), se asiste a una contra-reforma-respecto al período de hegemonía neoliberal- en el campo de la política social, en el cual se da un proceso de resignificación de la protección social. Destacan en este proceso las transformaciones en el sistema previsional y en el sistema de asignaciones familiares.

Con respecto al sistema previsional, el Programa de Inclusión Previsional del año 2005 junto a la re-estatización de los fondos en el año $2008^{10}$, permitieron aumentar el cociente entre los beneficios previsionales y la población en edad jubilatoria del 65,8\% en diciembre 2004 a 94\% en marzo 2010 (Groisman et al., 2011). Sumado a la expansión de la cobertura, hubo un fuerte incremento del haber previsional mínimo. En cuanto al sistema de asignaciones familiares, la Asignación Universal por Hijo ${ }^{11}$ puesta en marcha en el año 2009 instauró un seguro de protección social a la niñez destinada a hijos de personas desocupadas, que trabajan en el mercado informal o que ganan menos o igual que el salario mínimo, vital y móvil. Actualmente más de 3.500 .000 niños son

${ }^{10}$ La estatización de los fondos jubilatorios implicó la sustitución del Sistema Integrado de Jubilaciones y Pensiones establecido en el año 1994, en el cual los trabajadores podían optar por realizar sus aportes al régimen de reparto de administración estatal o realizarlos a un sistema de capitalización individual de administración privada en manos de las Administradoras de Fondos de Jubilaciones y Pensiones (AFJP); por la instauración del Sistema Integrado Previsional Argentino. De este modo, se eliminó el sistema de capitalización individual, se recreó el sistema único de reparto administrado por el Estado y se transfirieron los fondos acumulados en el sistema privado a la administración estatal. (Danani y Beccaria, 2001).

${ }^{11}$ Consiste en el pago mensual de 644 pesos (aproximadamente 80 dólares estadounidenses) para niños menores de 18 años. El $80 \%$ se cobra de manera mensual y el restante $20 \%$ acumulado anualmente se percibe luego de presentar los certificados de vacunación y control sanitario, y de acreditación de asistencia escolar. 
beneficiarios de esta asignación (Página Web de la Administración Nacional de la Seguridad Social).

Por último, y aún más relevante a los fines de este artículo, es a partir de 2003 que comienzan a advertirse políticas de promoción y protección del trabajo asociativo y autogestionado. En este contexto, el trabajo pretende realizar un aporte respecto a los avances que se instituyen en el sentido de la protección de los trabajadores no asalariados incluidos en estas políticas.

\section{LAS POLÍTICAS DE GENERACIÓN DE EMPLEO A PARTIR DE 1996: DE LOS PROGRAMAS DE EMERGENCIA OCUPACIONAL AL PROGRAMA ARGENTINA TRABAJA}

Tal como afirma Sennett en su célebre El Respeto (2003), en los sistemas de protección social, las personas toman conciencia de que sus derechos a la atención residen en su desvalimiento, en su padecimiento de necesidades. La necesidad se constituye en reflejo de debilidad, y ésta se posiciona en las antípodas del respeto por uno mismo y de los demás. El respeto no sólo se consigue a través de la autosuficiencia material, sino que ésta deber ser obtenida haciendo uso de la plenitud de las propias capacidades. La estima social que genera la autosuficiencia deriva del rechazo de la sociedad moderna al parasitismo y el derroche.

En contraposición a la pereza y el ocio, el trabajo es la fuente más importante del respeto mutuo y del respeto por uno mismo; y en el capitalismo industrial del siglo XIX éste se erige como valor moral absoluto. En este sentido, del mismo siglo data la distinción entre indigentes y trabajadores pobres, considerados los primeros no sólo pobres, sino también sujetos degradados y corruptos. Al incrementar tanto la autoestima como el respeto de los demás, se considera que el trabajo forma el carácter (Sennett, 2003).

Claro que lo que en la esfera pública es vivido como debilidad, no es percibido de la misma manera en la vida privada; ámbito en el cual la dependencia y la necesidad del otro son constituyentes de las relaciones -de amor, amistad y paternidad-. Es principalmente a partir del neoliberalismo que se desarrolla este "impulso a sacar a la gente de la dependencia" (Sennett, 2003: 109), extendiendo incluso las esferas dentro de las cuales las personas deben evitar caer en ella (educación, salud, seguro de desempleo, protección de los ancianos).

En la Argentina, esta lógica neoliberal imprimió su sello en las políticas de intervención en el desempleo a partir del año 1996 de la mano del workfare. Este esquema de política social provenía de los Estados de Bienestar de los países anglosajones. Ingresó a la política argentina mediante la Ley Nacional de Empleo sancionada en el año 1991 (Ley N²4.013) y se concretó en los progra- 
mas de emergencia ocupacional (Grondona, 2012). Esta reforma de la protección social implicó recortes en los criterios de elegibilidad y en la duración de los beneficios, así como un refuerzo de los mecanismos de re-vinculación con el mercado de trabajo, forzando a los beneficiarios a aceptar condiciones de trabajo no favorables. Además de esto, el esquema del workfare se constituía en "un tratamiento moral sobre la patología que aquejaba a esta población parasitaria de la asistencia (universalizada): la dependencia."(Grondona, 2012: 433). Dicho esquema nació bajo la sospecha del carácter moralmente desviado y tramposo de los beneficiarios. Inspirado en la concepción de sujeto pobre clásica del estado de bienestar liberal-anglosajón, en la cual se reconocen necesidades en lugar de derechos asociados al asalariado, la obligatoriedad de la prestación laboral de los programas condicionados de transferencia se sustentaba en una justificación moral tendiente a evitar la dependencia de los sujetos.

Generalmente, se conformó de dos tipos de programas: capacitación para los desempleados y esquemas de empleo transitorio. El workfare no se trataba de una política de creación de puestos de trabajo para los desempleados, sino de producción de trabajadores para empleos que nadie quería, o más aún, de trabajadores para empleos que no existían. En este sentido, en la Argentina, el workfare supuso la creación del espacio híbrido de la contraprestación; espacio transitorio pero vivido como permanente debido a que el pasaje a un nuevo programa era mucho más factible que el ingreso a un empleo (Grondona, 2012).

El primer esquema de workfare en la Argentina fue el Plan Trabajar inaugurado en el año 1996 (Grondona, 2012). El período abierto por este programa se destacó por el protagonismo que adquirió el Banco Mundial en el diseño y evaluación de las políticas sociales. El beneficio monetario se entregaba a cambio de trabajos públicos o comunitarios y en el año 1998 llegó a cubrir más de 1.100 .000 beneficiarios. El Programa fue de gestión local, mientras que los organismos responsables y ejecutores fueron organizaciones de la sociedad civil. La contraprestación laboral, según la normativa del Programa, cumplía con los objetivos de contribuir al desarrollo de las comunidades e incrementar la empleabilidad de las personas. El beneficio de 200 pesos $^{12}$ se encontraba por debajo del salario mínimo de mercado e incluso de la canasta básica, convirtiendo el trabajo en una especie de trabajo forzado, muy alejado de la concepción de trabajo como creación y fuente de desarrollo personal (Grondona, 2012).

Su principal sucesor fue el Plan Jefes y Jefas de Hogar Desocupados (PJJHD), el cual fue lanzado en el marco de la crisis de 2001 y la decretada emergencia

${ }^{12}$ Dado que en esos años regía el régimen de convertibilidad de la moneda, el beneficio equivalía a 200 dólares estadounidenses. 
ocupacional, marcando la masificación del workfare en la Argentina (Grondona, 2012). El Programa brindaba una ayuda económica a jefe/as de hogar desocupados con hijos de hasta 18 años de edad, de modo de garantizar su inclusión social (escolarización de los hijos, escolarización de los beneficiarios, controles de salud), a cambio de la realización de contraprestaciones laborales en proyectos comunitarios o de cursos de capacitación, con una dedicación horaria de entre cuatro y seis horas (Velásquez, 2010). Si bien se preveía la inclusión de 500.000 beneficiarios, debido a la profundidad de la crisis, el Programa llegó a cubrir a 2.000.000 de hogares en mayo de 2003, aproximadamente el $20 \%$ de los existentes en el país, llegando a tener una incidencia entre el 7\% y al 8\% en el total del empleo (Cortés, Groisman y Hoszowki, 2004; Golbert, 2007; Groisman, 2011; Groisman et al., 2011; Velásquez, 2010) ${ }^{13}$. El Programa contrastó por su magnitud con otros programas de empleo desarrollados durante la década del noventa, superando la suma de todos ellos: en 1997, año en que se distribuía el mayor número de beneficios, en el conjunto de los distintos programas de empleo no se alcanzaba a los 140.000 beneficios mensuales (Golbert, 2007). Con respecto a la transferencia monetaria, en el momento inicial, equivalía al $75 \%$ del salario mínimo; monto que se fue deteriorando hasta representar sólo el 23,8\% del salario mínimo en julio de 2005 (Golbert, 2007).

A partir del año 2003, se inició una progresiva disminución de la cantidad de beneficiarios del PJJHD, se mantuvo la misma retribución monetaria y se aumentaron las exigencias con el cumplimiento de las contraprestaciones (Natalucci y PaschkesRonis, 2011). Hacia el año 2007, los beneficiarios del PJJHD disminuyeron notablemente. Esto se debió a la combinación de dos factores: los efectos de la recuperación económica en el mercado de trabajo y la realización de un re-perfilamiento poblacional que distinguía entre vulnerables y empleables. A partir de este procedimiento, se dividió la población beneficiaria del esquema workfare entre el Programa Familias por la Inclusión para los primeros, considerados no empleables; y el Programa Seguro de Capacitación y Empleo para los segundos, con el fin de fortalecer sus capacidades e intermediar entre ellos y el mercado laboral (Grondona, 2012). El objetivo de este re-perfilamiento era dejar atrás de modo progresivo la política de contención que representaba el PJJHD para pasar a la implementación de políticas activas (Vuotto, 2013).

${ }^{13}$ A partir de 1995 los planes de empleo de emergencia fueron centrales para mantener el nivel de empleo y bajar la tasa de desempleo. En 2001, considerando a los beneficiarios de los planes de empleo como ocupados, el desempleo bajaba del 22\% al 20\% de la PEA, y en octubre del 2002, bajaba del 23.7\% al 17,9\% (Cortés et al., 2004). 
Asimismo, en el 2003 había comenzado a diseñarse otra estrategia de reperfilamiento de la población a través del fomento del asociativismo y la autogestión como salida de la pobreza, de modo de incluir a los beneficiarios del PJJHD en emprendimientos productivos enmarcados en la economía social (Vuotto, 2013; Natalucci y Paschkes Ronis, 2011). La promoción del trabajo asociativo y autogestionado obtuvo una fabulosa jerarquización en tanto estrategia central de política social - no económica ni de empleo- que buscaba reinsertar social y económicamente a los sectores excluidos y vulnerables ${ }^{14}$. La contracara de esta jerarquización como estrategia social fue el posicionamiento del trabajo asociativo y autogestionado en un lugar secundario del modelo socio-económico instaurado a partir de 2003 (Hopp, 2013).

Dos son los principales programas que se enmarcan en esta estrategia. En agosto de 2003 se pone en marcha el Programa Manos a la Obra del Ministerio de Desarrollo Social. Éste se plantea tres objetivos: contribuir a la mejora del ingreso de la población en situación de vulnerabilidad social, promover la economía social mediante el apoyo técnico y financiero, y fortalecer a organizaciones públicas y privadas, así como espacios asociativos y redes, a fin de mejorar los procesos de desarrollo local e incrementar el capital social, mejorar su efectividad y generar mayores capacidades y opciones a las personas, promoviendo la descentralización de los diversos actores sociales de cada localidad (Res. MD No 1.375/04). En este sentido, el programa se desarrolló a través de dos modalidades. Por un lado, el trabajo con las organizaciones estuvo a cargo del gobierno nacional. Por el otro, fueron principalmente los municipios quienes asumieron la gestión relacionada al subsidio de actividades de grupos de individuos (Natalucci y Paschkes Ronis, 2011). En el marco del Programa Manos a la Obra se firmaron convenios para la realización de 84 proyectos productivos de 17 organizaciones sociales que, se proyectaba, crearían 2.000 puestos de trabajo (Natalucci y Paschkes Ronis, 2011). A partir del año 2005, una reformulación del programa postuló la necesidad de enmarcar sus acciones en Proyectos Integrales de Desarrollo Regional definidos en Mesas Locales de Actores, las cuales debían priorizar proyectos de acuerdo a su propia definición de la problemática de la economía social en la región. La segunda gran iniciativa dentro de las políticas de promoción de la economía social

${ }^{14}$ Los programas incluidos en esta línea pueden ser considerados políticas socio-productivas (Hopp, 2012). Las mismas son definidas como intervenciones sociales del Estado en dos sentidos. Por un lado, son políticas sociales porque su objetivo es la reproducción de la vida de los individuos y las sociedades. Por el otro, pueden considerarse como políticas económicas-laborales que, mediante prestaciones económicas, intervienen en la distribución primaria del ingreso, estimulando la producción para el mercado. 
y el trabajo asociativo, es el Programa de Ingreso Social con Trabajo -o Programa Argentina Trabaja- surgido en el año 2009. Este Programa, es el objeto de análisis directo de este artículo, razón por la cual profundizaremos en sus características e implicancias en el próximo apartado.

\section{EL PROGRAMA ARGENTINA TRABAJA}

En esta sección analizaremos el Programa Argentina Trabaja principalmente en términos de los grados de protección social a los que acceden los trabajadores que se insertan en el mismo, los cuales pertenecen a una categoría más amplia de trabajadores asociativos y autogestionados. Asimismo, señalaremos las innovaciones y continuidades que establece en el contexto de la política social argentina.

El Programa Ingreso Social con Trabajo, más comúnmente conocido como Argentina Trabaja ${ }^{15}$, fue creado en el año 2009, en el marco del desaceleramiento del crecimiento económico producto de la crisis internacional de 2009. Esta crisis le había demostrado al gobierno nacional que el crecimiento económico experimentado durante los años anteriores no había sido suficiente para integrar al mercado de trabajo a sectores sociales excluidos. En este sentido, el gobierno nacional profundizó el enfoque de política socio-laboral que venía desarrollando desde el 2003 en el cual destacaba la generación de empleo a través de la política social (Hopp y Frega, 2012).

Anunciado por la presidenta Cristina Fernández de Kirchner el 14 de agosto de 2009 por cadena nacional, el PAT comenzó a implementarse en el mes de octubre y se estimó que crearía 100.000 puestos de trabajo. En el discurso de lanzamiento del Programa, Cristina Fernández de Kirchner precisó que la primera etapa tendría un costo de 1.500 millones de pesos (aproximadamente 400 millones de dólares estadounidenses en el año 2009) y estaría focalizada en el conurbano bonaerense, al cual le seguirían otras zonas geográficas con esa "densidad de vulnerabilidad social" (Diario Clarín, 15 de agosto de 2009). Desde el discurso oficial se enfatizó en la novedad del abordaje que propuso el Programa: dado que "tiende a que la gente tenga trabajo y se organice socialmente", se diferencia de los esquemas asistencialistas de política social (Diario Clarín, 15 de agosto de 2009). El beneficio monetario se percibiría en cuentas personales, a través de tarjetas bancarias, de modo de evitar

\footnotetext{
${ }^{15}$ El Programa Ingreso Social con Trabajo es una línea de acción del Programa Argentina Trabaja, junto con Proyectos Socioproductivos "Manos a la Obra", Marca Colectiva, Microcréditos, y Monotributo Social. No obstante, suele referirse comúnmente al Programa Argentina Trabaja para designar solamente la línea del Programa Ingreso Social con Trabajo.
} 
mediadores políticos y garantizar la transparencia del procedimiento. Finalmente, otra de las innovaciones destacadas en aquella oportunidad fue que los beneficiarios del Programa serían inscriptos en el monotributo social ${ }^{16}$. En esa misma oportunidad resulta sugerente el diagnóstico que la Presidenta realizó sobre la pobreza, haciendo referencia al problema de la inequidad en la Argentina ${ }^{17}$, en detrimento de los discursos que consideran la pobreza como un problema de carencia individual.

De la descripción oficial del PAT, se desprende que actúa a través de la generación de puestos de trabajo, la capacitación y la promoción de la organización cooperativa para la ejecución de obras de infraestructura. Está dirigido a personas en situación de vulnerabilidad, es decir, sin ingresos formales en el grupo familiar, ni pensiones, jubilaciones u otros planes sociales, a excepción del Plan Nacional de Seguridad Alimentaria (Página web del Ministerio de Desarrollo Social). Este primer paso en la identificación de la población objetivo es seguido de un proceso de evaluación de los potenciales beneficiarios mediante una visita domiciliaria y la aplicación de una encuesta socioeconómica. En su implementación, los Entes Ejecutores (municipios, provincias, federaciones y/o mutuales), a través del Instituto Nacional de Asociativismo y Economía Social (INAES), forman y capacitan cooperativas compuestas por alrededor de 30 trabajadores cada una ${ }^{18}$, las cuales realizan obras públicas locales mano de obra intensivas.

Según los últimos datos disponibles, en el año 2012 eran 202.178 los cooperativistas incorporados al Programa de Ingreso Social con Trabajo (Memoria detallada del estado de la Nación, 2013), mientras que la cantidad desciende

${ }^{16}$ El monotributo social es un régimen tributario optativo, creado con el objeto de facilitar y promover la incorporación a la economía formal de aquellas personas en situación de vulnerabilidad social que han estado históricamente excluidas. A partir de la inscripción en el mismo, los contribuyentes están en condiciones de emitir facturas, ser proveedores del Estado por contratación directa, acceder a las prestaciones de las obras sociales del Sistema Nacional de Salud e ingresar al sistema previsional (jubilación). Además, los monotributistas sociales no pierden el acceso a la Asignación Universal por Hijo. En todos los casos, deben tratarse de emprendedores en situación de vulnerabilidad social que no generen ingresos anuales superiores a 48.000 pesos, monto vigente desde el mes de septiembre de 2013. Los contribuyentes sólo deben abonar el monto correspondiente al $50 \%$ del componente de la obra social. Los componentes impositivos y de aportes previsionales son subsidiados por el Estado nacional (Página web del Ministerio de Desarrollo Social de la Nación).

17 "No vamos a discutir si es 15, 20 o 30 [el porcentaje de la pobreza] (...) En la Argentina hay pobres, pero el problema es la inequidad [que es] la verdadera fábrica de pobres". (Diario Clárin, 15 de agosto de 2009)

${ }^{18}$ El Programa comenzó constituyendo cooperativas de 60 personas. En el año 2012, a través de la resolución 1499/2012, éstas pasaron a conformarse con 30 trabajadores. 
a 131.800 si se consideran los titulares que se mantienen activos (Secretaría de Comunicación Pública, 21 de junio de 2013). En junio de 2011, los beneficiarios estaban conformados por hombres y mujeres, con bajos niveles de instrucción (el 80\% no había concluido los estudios secundarios), en proporciones casi semejantes (53\% de mujeres y 47\% de hombres) (Ministerio de Desarrollo Social, 2011). El 38\% pertenecía a hogares de jefatura femenina y casi la mitad provenía de empleos precarios (49\%) (Ministerio de Desarrollo Social, 2011). Los beneficiarios del Programa pertenecen a las provincias de Buenos Aires, Tucumán, Corrientes, Mendoza, Entre Ríos, Salta, Santiago del Estero, San Juan, La Rioja, Río Negro, Misiones, Catamarca y San Luis.

Con respecto a la cantidad de cooperativas formadas, en noviembre de 2011 se verificaba la existencia de 2.107 (Pedido de Acceso a la Información, 2011). Hacia marzo de 2013, en el discurso de apertura de las sesiones ordinarias del Congreso de la Nación, la presidenta Cristina Fernández de Kirchner afirmó que el número de cooperativas ascendía a 6.626 .

En el año 2009, al momento del lanzamiento del Programa, el ingreso de los participantes se definió en 1200 pesos (aproximadamente 320 dólares estadounidenses). En febrero de 2012 se percibió un significativo aumento: a los 1200 pesos de ingreso básico (aproximadamente 280 dólares estadounidenses) se sumaron 300 pesos por productividad y 250 pesos por presentismo (aproximadamente 130 dólares estadounidenses en total) (Cristina Fernández de Kirchner, 28 de febrero de 2012). Finalmente, el último aumento llegó en abril de 2013, momento en el cual se anunció un aumento de 250 pesos (100 pesos por presentismo y 150 pesos por productividad), llegando a ubicarse en 2000 pesos (aproximadamente 400 dólares estadounidenses) el haber percibido por los trabajadores de las cooperativas de trabajo (Cristina Fernández de Kirchner, 14 de marzo de 2013).

El Programa se erige sobre la reivindicación del trabajo en tanto es considerado "el mejor organizador e integrador social y constituye la herramienta más eficaz para combatir la pobreza y distribuir la riqueza" (Página web del Ministerio de Desarrollo Social de la Nación). Vuotto (2013) afirma que el PAT se inscribe en un enfoque integracionista, el cual se caracteriza por convertir al empleo en el elemento de inserción, dado que éste condiciona los ingresos, la identidad y la autoestima. A diferencia de este enfoque, el de la pobreza considera que ésta es una cuestión de insuficiencia de recursos; y el de la marginalidad diagnostica una "cultura de la dependencia" o "cultura de la pobreza" en los individuos situados fuera de las normas sociales y por lo tanto los considera, en parte, responsables de su estado de pobreza. 
En este sentido, desde el Ministerio de Desarrollo Social se afirma que este programa de inclusión social realiza, por un lado, inversiones para generar oportunidades de desarrollo de capacidades socio ocupacionales, y a la vez realiza transferencias monetarias directas a los titulares que desarrollen actividades, a modo de incentivos para la inclusión social. Estas actividades son consideradas como "puentes" formativos, integrativos y de revalorización de hábitos y capacidades individuales y colectivas (Pedido de Acceso a la información, 2011: 4).

Dado que exige una contraprestación a cambio del beneficio, la iniciativa parece inscribirse en las líneas del workfare descripto en el apartado anterior. No obstante, el PAT plantea una diferencia no menor: lleva a cabo esta exigencia, más que a través de una contraprestación, a partir de la creación y apoyo de cooperativas de trabajo, en un intento por generar "empleo digno y genuino", acción considerada la "mejor política social" (Página web del Ministerio de Desarrollo Social de la Nación). Se afirma que el PAT se constituye en una herramienta especial para el entrenamiento en la cultura del trabajo y para el redescubrimiento de la autoestima mediante la realización de acciones útiles para sí mismos y para otros (Pedido de Acceso a la información, 2011).

En numerosas oportunidades, el gobierno nacional, encarnado en distintos funcionarios, enfatizó en la voluntad de sustituir la figura del "beneficiario" de planes sociales por la de "trabajador con derechos y obligaciones" (Vuotto, 2013). En este sentido, la Presidenta enfatizó en varias oportunidades en la "vuelta de tuerca cardinal" que se estaba llevando a cabo en materia social (28 de febrero de 2012). En sus propias palabras, esta vuelta se daba porque:

Decidimos -a partir del año 2003- que no podía haber más beneficiarios en material social; beneficiarios indica asistencialismo, nosotros creemos en la promoción y en la inclusión y fundamentalmente en la organización de la sociedad. Porque tener una cooperativa, organizarse junto a otros para llevar un objetivo, para tener una meta, para fijarse un tiempo es organizar a la sociedad, aprender a organizarse.

A partir de un diagnóstico acerca del Programa que lo posicionó como un ámbito de contención y generación de espacios de trabajo, así como un entorno propicio para la capacitación y la terminalidad educativa, en el año 2012 se planteó la necesidad de proporcionar oportunidades superadoras (Vuotto, 2013). En este sentido, durante ese año se sucedieron una serie de cambios respecto a la estructuración de las cooperativas, los criterios de remuneración y las condiciones de trabajo (Res. 1499/2012). Uno de los cambios más importantes fue la disminución en el número de integrantes de las cooperativas: de 60 integrantes pasaron a ser 30 . Por otro lado, las cooperativas volvieron a elegir 
autoridades y se comenzó a tomar en consideración la ubicación geográfica de sus integrantes. Otro de los cambios más relevantes refiere a la remuneración; es en este momento que se pasa de los $\$ 1.200$ a los $\$ 1.750$. Por último, la jornada laboral se redujo de seis a cuatro horas para favorecer la asistencia a talleres de capacitación. En este sentido, el diseño del PAT, así como los cambios introducidos en el mismo a partir del año 2012, intentan constituir la figura del "trabajador con derechos y obligaciones" mencionada.

A continuación repasaremos las principales innovaciones que supuso el PAT. En primer lugar, la centralidad que revistió el trabajo como núcleo de organización (Natalucci y Paschkes Ronis, 2011). Si bien, las experiencias de workfare databan de varios años y el Ministerio de Desarrollo Social ya había implementado programas de corte productivo, la realización de las contraprestaciones nunca había sido rigurosamente controlada ni se había enmarcado en la generación de cooperativas desde el propio programa. En el caso del PAT se establecieron mecanismos que permiten comprobar el cumplimiento de las horas y del trabajo, y se dispone de formas de sanción que llegan a incluir la exclusión del Programa. Por ejemplo, la suma de dinero que perciben los integrantes del programa por el presentismo conlleva el control de las asistencias, las cuales de no cumplirse significan la pérdida de dicho plus. En segundo lugar, la forma cooperativa de organizar el trabajo de los beneficiarios (Natalucci y Paschkes Ronis, 2011). Esto implicó un aprendizaje de ambos lados. Por su parte, el Ministerio debió poner en marcha capacitaciones ${ }^{19}$ y asistencia técnica para garantizar el funcionamiento cooperativo del colectivo de trabajadores. Si bien las cooperativas pueden no funcionar como tales desde los comienzos, son múltiples los esfuerzos en capacitación diseñados desde el Ministerio de Desarrollo Social. Por otro lado, los trabajadores debieron adentrarse en esta modalidad de organización productiva y, aunque quizá en dimensiones menores a las proyectadas, múltiples colectivos de trabajadores han logrado adquirir grados importantes de cohesión y autonomía, lo que los posiciona en un lugar privilegiado para diseñar proyectos productivos de gestión asociada. Otra de las características innovadoras del programa es que a pesar de que mantuvo su carácter focalizado, al igual que los anteriores programas de políti-

\footnotetext{
${ }^{19}$ Destaca en este sentido la Diplomatura de Operador Socioeducativo en Economía Social y Solidaria dirigida a trabajadores del Programa. Este diploma de Extensión Universitaria se desarrolla en forma conjunta entre el Ministerio de Desarrollo Social de la Nación y el Ministerio de Educación de la Nación en convenio con Universidades nacionales. En su primera edición (2010-2011) cursaron aproximadamente 900 cooperativistas y se diplomaron 675. En su segunda edición (2012-2013) cursaron 2800 trabajadores. (Pastore et al., 2013).
} 
ca socio-laboral, su masividad contrarrestó el carácter selectivo que estos programas venían operando al momento de la implementación de los mismos, y sobre todo, al momento de la distribución de los beneficios (Natalucci y Paschkes Ronis, 2011). La selección de los beneficiarios -claro que al interior de las zonas geográficas consideradas las más vulnerables- se implementó a través de modalidades que procuraron no constituir sujetos de la beneficencia, sino integrarlos a partir del cooperativismo de trabajo. Por último, la innovación principal desde la mirada de este análisis refiere a las prestaciones sociales (obra social y aportes previsionales) a las que accedieron los cooperativistas a través del monotributo social. Hacia junio de 2011, 157.745 integrantes del Programa Argentina Trabaja estaban incluidos en el sistema de salud gracias a los aportes a obra social realizados a través del monotributo social (Ministerio de Desarrollo Social, 2011). Un aspecto positivo a destacar es el proceso de ampliación de la seguridad social mediante la creación de la Asignación Universal por Hijo. En su carácter de monotributistas sociales, los trabajadores de las cooperativas del PAT han sido incorporados al sistema de asignaciones familiares. De este modo, aunque de manera precaria en relación al trabajo asalariado registrado en la seguridad social, los beneficiarios del Programa acceden a un abanico de mecanismos de protección social que los posiciona ventajosamente respecto a la situación de informalidad de la cual la mitad de ellos provienen.

Ahora bien, una vez repasadas las voces oficiales en torno al PAT y pasar revista a sus elementos más innovadores, realizamos una aproximación desde la implementación del Programa en el territorio, la cual nos permitirá conocer las tensiones que se juegan en la misma. Para realizar este análisis, haremos uso del trabajo de Hopp y Frega (2012), el cual cuenta con un sólido trabajo de campo. El principal aporte de estas autoras radica en la identificación de obstáculos para la consecución del objetivo de generación de cooperativas de trabajo como alternativas laborales sostenibles; obstáculos que dan cuenta de una tensión entre trabajo asociativo y autogestionado, y política social asistencial. Las autoras subrayan que los mismos se hallan en la forma en que las cooperativas se constituyen, en los vaivenes burocráticos, y en las disputas por la autonomía de las organizaciones respecto de los recursos estatales. Esta tensión se manifiesta concretamente en: a) la modalidad de constitución de las cooperativas y la forma de pago del subsidio, y b) la organización de las tareas que realizan las cooperativas y las condiciones laborales. Ambas dimensiones de la tensión tienen como consecuencia un tercer elemento, c) las dificultades tanto materiales como simbólicas para sostener la cooperativa en tanto alternativa laboral decente (Hopp y Frega, 2012). 
En cuanto al primer punto, las cooperativas son conformadas desde los entes estatales, ajustándose a criterios que pueden desestimar los de pertenencia organizacional y/o barrial, y por lo tanto, dejar de lado el objetivo de organización de la sociedad. Por otra parte, la compra de los materiales y las herramientas necesarios para la realización de las actividades es llevada adelante por los gobiernos provinciales o municipales mediante el financiamiento del gobierno nacional (Res. MDS 3182/09). Con respecto al pago de los haberes, a pesar de ganar en transparencia a través de la transferencia de los subsidios individuales a las cuentas bancarias personales de cada cooperativista, esto actúa en detrimento de la efectiva constitución de la cooperativa de trabajo. La no mediación de la cooperativa en tanto colectivo autogestionado de trabajadores, instaura una lógica individualizante contraria a las prácticas del cooperativismo.

En cuanto a la organización de las tareas que realizan las cooperativas, las situaciones son diversas. Existen cooperativas que alcanzan altos grados de autonomía en el diseño e implementación de las actividades. Estas cooperativas suelen partir de grupos de militancia pre-constituidos y sus miembros generalmente pertenecen, en términos formales, a distintas cooperativas. No obstante, exceptuando estos grupos, las posibilidades de llevar a cabo los propios proyectos productivos resultan sumamente dificultosas para colectivos de trabajadores sin experiencia previa en cooperativismo ni militancia compartida. En este sentido, las cooperativas generalmente se ciñen a la ejecución de obras de infraestructura o mejoramiento barrial diseñadas y determinadas por las instancias gubernamentales, y no por la propia cooperativa. Con respecto a las condiciones laborales, a pesar de que los ingresos son de un monto alto en comparación a otros programas sociales, éste no llega a igualar al salario mínimo, vital y móvil ${ }^{20}$. Por otro lado, tampoco permite contar con un trabajo que, por la cantidad de horas que implica, permita acceder a recursos suficientes para obtener condiciones de vida dignas. Sumado a esto, los ingresos no son actualizados según los valores de la canasta básica familiar. Por esto, el ingreso que perciben los cooperativistas no se asemeja completamente al salario de un trabajador formal en relación de dependencia, ni al retiro a cuenta de utilidades

${ }^{20}$ El Salario Mínimo Vital y Móvil se define como "la menor remuneración que debe percibir en efectivo el trabajador sin cargas de familia, en su jornada legal de trabajo, de modo que le asegure alimentación adecuada, vivienda digna, educación, vestuario, asistencia sanitaria, transporte y esparcimiento, vacaciones y previsión". El valor del mismo se establece en forma tripartita en el marco del Consejo del Empleo, la Productividad y el Salario Mínimo Vital y Móvil. (Página web del Ministerio de Trabajo, Empleo y Seguridad Social de la Nación). Actualmente se encuentra en los 3.600 pesos (aproximadamente 450 dólares estadounidenses). 
por el trabajo realizado en una cooperativa. En cuanto a la construcción de marcos legales y regulatorios para la forma de trabajo cooperativa que se fomenta desde el PAT, destacan la creación del Registro Nacional de Efectores de la Economía Social a través del cual se accede al monotributo social; y la sanción de la Ley de Microcrédito que les permite a las cooperativas -y demás miembros de emprendimientos de la economía social- que deseen desarrollar su propio proyecto productivo acceder a financiamiento barato -aunque también con montos muy bajos-. Sin embargo, las formas de protección social a las que da lugar este marco regulatorio son limitadas. El monotributo social presenta limitaciones respecto al acceso y la calidad a las prestaciones que ofrece (Hopp, 2013).

Múltiples son las innovaciones que introduce el Programa. Desde la perspectiva de este trabajo, destaca la inclusión de los trabajadores en el monotributo social y la generación de cooperativas de trabajo más que la exigencia de contraprestaciones laborales tradicionales e individuales. No obstante, las condiciones de desprotección respecto a los ingresos, las modalidades de protección social, y las tensiones que atraviesan las cooperativas en la implementación concreta del PAT en los territorios, limitan las posibilidades de afianzar la estrategia de generación de trabajo "de calidad", es decir, con acceso pleno a la protección social.

\section{CONCLUSIONES}

A lo largo de este trabajo, hemos realizado un abordaje del Programa Argentina Trabaja desde la perspectiva de la protección social, de modo de visibilizar los modos de protección que instaura, y las innovaciones y limitaciones que introduce en el campo de la política socio-laboral de cara a la generación de trabajo "de calidad".

Iniciamos el escrito realizando una revisión de los principales conceptos necesarios para llevar a cabo el análisis propuesto, para luego repasar brevemente el devenir de la protección social en la Argentina. La evolución de la misma dio cuenta de importantes transformaciones. Partiendo de una situación de amplia cobertura hasta la década del setenta, la protección social se vio debilitada frente a la creciente mercantilización de la fuerza de trabajo y de las necesidades sociales. De la mano de estas transformaciones, la política social también atravesó fuertes mutaciones. Destacan la introducción del esquema workfare en la política socio-laboral de la década del noventa, la redefinición de la cuestión social y de los patrones de integración social. El análisis de estos cambios resultó ineludible de cara al conocimiento de los cambios y las continuidades en cuanto a la protección social que plantea el momento actual. 
Con la introducción del workfare en la Argentina, a partir del Plan Trabajar en el año 1996, la generación de trabajo como modalidad de intervención en lo social sería cada vez más frecuente. A partir del año 2003, como producto de la profunda crisis social, política y económica que había atravesado el país en los años 2001-2002, las modalidades de protección social se fueron redefiniendo. En un contexto de contra-reforma en el campo de la política social respecto a la década del noventa, el fomento del asociativismo y el trabajo autogestionado en el marco de la economía social se transformó en la estrategia fundamental del Ministerio de Desarrollo Social para la generación de trabajo "de calidad". En el año 2009 surgió el Programa Argentina Trabaja con el objetivo explícito de crear fuentes de trabajo a través de la creación de cooperativas de trabajo para la realización de obras de infraestructura local. Como dimensión privilegiada de la calidad de un trabajo consideramos el grado en que permite la integración social de un sujeto, y por lo tanto observamos la protección social a la que permite acceder aquel trabajo.

El análisis del Programa Argentina Trabaja permitió identificar innovaciones y aspectos positivos en este sentido, entre las que destacan la inscripción de los beneficiarios en el monotributo social, la posibilidad de percibir la Asignación Universal por Hijo y por Embarazo, y la conformación de cooperativas como modalidad de trabajo en lugar de exigir la contraprestación tradicional de los programas sociales previamente existentes. Por otro lado, la masividad del PAT, junto al ingreso -mayor al de programas de transferencia de ingresos anteriores- percibido por los trabajadores, son elementos que suman potencialidad a los cambios que se proponen desde el diseño.

No obstante, la revisión de la literatura existente sobre el Programa, nos permite delinear tensiones y limitaciones que derivan fundamentalmente de su carácter híbrido (Hopp, 2013), en tanto posee elementos que tienden al posicionamiento del trabajo asociativo como una vía para la integración social, y por otro lado, al uso del trabajo como un recurso de la asistencia. En este segundo sentido, resaltan las escasas posibilidades de diseñar e implementar las actividades que se llevan a cabo en el marco de la cooperativa de manera autogestiva; el hecho de que los ingresos sean percibidos de manera individual, y que los mismos no alcancen el salario mínimo vital y móvil, ni sean actualizados según los estándares del empleo asalariado formal; así como los límites que aún acarrea el monotributo social en cuanto al efectivo uso de los beneficios que contempla.

En síntesis, la protección social que instaura el Programa genera un mejoramiento de las condiciones de vida de sectores sociales provenientes de las filas de la informalidad y el desempleo. A partir de formas alternativas de trabajo 
como lo es la participación en cooperativas, brinda mayores grados de protección social, contribuyendo a la construcción de trabajo "de calidad". No obstante, en comparación con la protección social destinada al empleo formal asalariado, evidencia sus debilidades y el largo camino por recorrer.

El análisis realizado no pretende soslayar las potencialidades que contiene una política social que busca -y en algunos aspectos lo consigue exitosamente- ampliar los grados de protección a los que acceden sectores sociales largamente excluidos, a través de la generación de trabajo asociativo y autogestionado como una vía de integración social.

\section{REFERENCIAS BIBLIOGRÁFICAS}

Basualdo, E. (2003). "Las reformas estructurales y el Plan de Convertibilidad durante la década de los noventa. El auge y la crisis de la valorización financiera". Realidad Económica, 200, 42-83.

Castel, R. (1995). La metamorfosis de la cuestión social. Una crónica del salariado. Disponible online: https://catedracoi2.files.wordpress.com/2013/05/castel-robertla-metamorfosis-de-la-cuestic3b3n-social.pdf

Castel, R. (2012). El ascenso de las incertidumbres. Trabajo, protecciones, estatuto del individuo. Buenos Aires: Fondo de Cultura Económica.

Castel, R. (2013). "Políticas del riesgo y sentimiento de inseguridad". En Castel, R., Kessler, G., Merklen, D., Murand, N. Individuación, precariedad, inseguridad. ¿Desindustrialización del presente? Buenos Aires: Editorial Paidós, 33-43.

Cortés, R., F. Groisman y A. Hoszowki (2004). "Transiciones ocupacionales: el caso del plan jefes y jefas". Realidad Económica, 202.

Curcio, J. (2011). "Descripción del Sistema de Seguridad Social: componentes al cabo de la década del '90 y de la primera década del siglo XXI. En Danani, C.; Hintze, S. (coord.). Protecciones y desprotecciones: la seguridad social en la Argentina 19902010. Los Polvorines: Universidad Nacional de General Sarmiento, 33-60.

Curcio, J.; Beccaria, A.; Fournier, M. (2011). "Sistema de Seguridad Social y mercado de trabajo: evolución de la cobertura en la Argentina entre 1990 y 2010". En Danani, C.; Hintze, S. (coord.). Protecciones y desprotecciones: la seguridad social en la Argentina 1990-2010. Los Polvorines: Universidad Nacional de General Sarmiento, 61-101.

Damill, M. y R. Frenkel (2006). "El mercado de trabajo argentino en la globalización financiera". Revista de la Cepal, 88.

Danani, C. (2009). "La gestión de la política social: un intento de aportar a su problematización”. En Chiara, M. y M.M. Di Virgilio (Org.). La gestión de la política social. Conceptos y herramientas. Buenos Aires: UNGS-Editorial Prometeo, 11-34.

Danani, C.; Beccaria, A. (2011). "La (contra) reforma previsional argentina 2004-2008: aspectos institucionales y político-culturales del proceso de transformación de la protección". En Danani, C.; Hintze, S. (coord.). Protecciones y desprotecciones: la seguridad social en la Argentina 1990-2010. Los Polvorines: Universidad Nacional de General Sarmiento, 103-151. 
Danani, C.; Hintze, S. (2011). "Introducción. Protección y seguridad social para distintas categorías de trabajadores: definiciones conceptuales, propuestas de abordaje e intento de interpretación". En Danani, C.; Hintze, S. (coord.). Protecciones y desprotecciones: la seguridad social en la Argentina 1990-2010. Los Polvorines: Universidad Nacional de General Sarmiento, 9-29

Esping-Andersen, G. (1993). Los tres mundos del Estado del Bienestar. Valencia: Edicions Alfons El Magnánim/Generalitat Valenciana/Diputació Provincial de Valéncia.

Esping-Anderson, G.; Palier, B. (2011). Los tres grandes retos del Estado del bienestar. Barcelona: Ariel.

Fernández Alvarez, M. I. (2007). "En defensa de la fuente de trabajo": demandas y prácticas de movilización en una empresa recuperada de Buenos Aires." Avá. Revista de Antropología, 11, 63-85.

Golbert, L. (2007). "Argentina: aprendizajes del Programa Jefes y Jefas de Hogar Desocupados". En Arriagada, I (ed.) Familias y políticas públicas en América Latina: una historia de desencuentros. Santiago de Chile: CEPAL.

Grassi, E. (2012). "Política sociolaboral en la Argentina contemporánea. Alcances, novedades y salvedades." Revista de Ciencias Sociales de la Universidad de Costa Rica, 135-136, 185-198.

Groisman, F. (2010). "Inestabilidad de ingresos y desigualdad durante la reciente fase de recuperación económica en Argentina”. Estudios del Trabajo, 36.

Groisman, F. (2011). "Argentina: Los hogares y los cambios en el mercado laboral (2004-2009)". Revista de la CEPAL, 104.

Groisman, F., F. Bossert, M.E. Sconfienza (2011). Políticas de protección social y participación económica de la población en Argentina (2003-2010). En VI Jornadas de Jóvenes Investigadores, Instituto de Investigaciones Gino Germani, Universidad de Buenos Aires. 10, 11 y 12 de noviembre de 2011.

Grondona, A. (2012). "Tradición" y "traducción": un estudio de las formas contemporáneas del gobierno de las poblaciones desempleadas en la Argentina." Tesis de Doctorado de Ciencias Sociales de la Universidad de Buenos Aires. Biblioteca Virtual del Centro Cultural de la Cooperación Floreal Gorini.

Hintze, S. (2013). "Las políticas públicas de promoción del trabajo asociativo autogestionado en América Latina". Revista del Observatorio Social sobre Empresas Recuperadas y Autogestionadas, 9.

Hopp, M. (2012). "La sostenibilidad de los emprendimientos asociativos y autogestionados: Reflexiones para la construcción de la Economía Social en Argentina". Revista Org E Demo, 12 (2), 39-58.

Hopp, M. (2013). "Políticas de promoción del trabajo asociativo y autogestionado en la Argentina actual: un balance". Revista del Observatorio Social sobre Empresas Recuperadas y Autogestionadas, 9.

Hopp, M.; Frega, M. (2012). "Trabajo asociativo y políticas sociales: Tensiones y potencialidades en la experiencia de implementación del Programa Argentina Trabaja”. Revista Debate Público. Reflexión de Trabajo Social, 2 (3), 71-81. 
Kessler, G.; Merklen, D. (2013). "Una introducción cruzando el Atlántico". En Castel, R., Kessler, G.,Merklen, D., Murand, N. Individuación, precariedad, Inseguridad. ¿Desinstitucionalización del presente? Buenos Aires: Editorial Paidós, 9-31.

Maneiro, M. (2012). De Encuentros y desencuentros. Estado, gobiernos y movimientos de trabajadores desocupados. Buenos Aires: Editorial Biblos.

Memoria detallada del estado de la Nación, año 2012. $1^{\circ}$ de marzo de 2013. Buenos Aires: Presidencia de la Nación.

Merklen, D. (2013). "Las dinámicas contemporáneas de la individuación". En Castel, R., Kessler, G.,Merklen, D., Murand, N. Individuación, precariedad, Inseguridad. ¿Desinstitucionalización del presente? Buenos Aires: Editorial Paidós, 45-86.

Ministerio de Desarrollo Social (2011). Ejecución del Programa: Principales resultados al primer semestre 2011. Perfil de titulares. Disponible online: http://www.desarrollosocial.gob.ar/Uploads/i1/PRISTresultados2011.pdf (fecha de consulta: 20 de enero de 2014)

Natalucci, A.; Paschkes Ronis, M. (2011). “Avatares en la implementación de políticas sociales. Concepciones y prácticas de las organizaciones sociopolíticas que participan en el programa Argentina Trabaja (2009-2010)". En Ana Arias; Alejandra Bazzalo; Bárbara García Godoy. Políticas públicas y Trabajo Social. Aportes para la reconstrucción de lo público. Buenos Aires: Editorial Espacio.

Palomino, H. (2008). "La instalación de un nuevo régimen de empleo en Argentina: de la precarización a la regulación". Revista Latinoamericana de Estudios del Trabajo, 13 (19), 121-144.

Pastore, R; Tedeschi, L.; Iglesias, M. F; Plasencia, A.; Basterrechea, M; Repetto, V.; Haddad, V; Barrios, A. (2013). Módulo de Economía Social y Solidaria. Buenos Aires: UNQ-UNM-UNSAM-MDS.

Polanyi, K. (2007). La gran transformación. Crítica del liberalismo económico. Buenos Aires: Fondo de Cultura Económico.

Sennett, R. (2003). El respeto. Sobre la dignidad del hombre en un mundo de desigualdad. Barcelona: Anagrama.

Sennett, R. (2012). La corrosión del carácter. Las consecuencias personales del trabajo en el nuevo capitalismo. Barcelona: Editorial Anagrama.

Soldano, D; Andrenacci, L. (2006). "Aproximación a las teorías de la política social a partir del caso argentino". En Andrenacci, L. Problemas de politica social en la Argentina contemporánea. Buenos Aires: Prometeo.

Tokman, V. (2006). Inserción laboral, mercados de trabajo y protección social. Serie Financiamiento del Desarrollo 170. Santiago de Chile.

Velásquez, M. (2010). Seguros de desempleo y reformas recientes en América Latina (Serie macroeconomía del desarrollo $N^{\circ}$ 99). Santiago de Chile: División de desarrollo económico-CEPAL-Naciones Unidas.

Vuotto, M. (2013). "Las oportunidades de inclusión en iniciativas de la economía social en la Argentina: consideraciones sobre el programa Ingreso Social con Trabajo". En Novena Conferencia Regional ISTR LAC Participación y Representación:nuevos 
paradigmas para la sociedad civil latinoamericana. Santiago de Chile, 28 al 30 de agosto de 2013. Disponible en: http://www.lasociedadcivil.org/docs/ciberteca/IS TR2013/mirta_vuotto.pdf (consultado el 15 de enero de 2014)

\section{LEYES Y RESOLUCIONES}

Ley $\mathrm{N}^{\circ} 24.013$ (Ley Nacional de Empleo)

Resolución MDS No 1375/04

Resolución MDS No 3182/09

Resolución MDS No 1499/12

\section{PÁGINAS WEB CONSULTADAS}

Página web del Ministerio de Desarrollo Social de la Nación: http://www.desarrollosocial.gov.ar/

Página web de Administración Nacional de la Seguridad Social (ANSeS): http://www. anses.gob.ar/

Página web del Ministerio de Trabajo, Empleo y Seguridad Social de la Nación: http:// www.trabajo.gov.ar/

\section{DISCURSOS-PRESIDENCIA DE LA NACIÓN}

Cristina Fernández de Kirchner. 28 de febrero de 2012. Acto sobre anuncios de temas de Desarrollo Social: Palabras de la Presidenta de la Nación. Disponible en: http://www. presidencia.gov.ar/discursos/25720-acto-sobre-anuncios-de-temas-de-desarrollosocial-palabras-de-la-presidenta-de-la-nacion

Cristina Fernández de Kirchner. 1 de marzo de 2013. Inauguración del $131^{\circ}$ periodo de sesiones ordinarias del Congreso: Discurso de la Presidenta de la Nación. Disponible en: http://www.presidencia.gob.ar/discursos/26370-inauguracion-del-131o-periodo-de-sesiones-ordinarias-del-congreso-discurso-de-la-presidenta-de-la-nacion

\section{ENTRADAS DE FACEBOOK}

Cristina Fernández de Kirchner. 14 de marzo de 2013. Presentación del plan "Ellas Hacen" para 100.000 mujeres. Disponible en: https://www.facebook.com/media/set/?set=a.51 $1165998947940.1073741829 .115689108495633 \&$ type $=1$

\section{CABLES DE PRENSA-PRESIDENCIA DE LA NACIÓN}

Secretaría de Comunicación Pública, Sala de Prensa, República Argentina. 21 de junio de 2013. 130 mil cooperativistas en el Plan Argentina Trabaja. Disponible en: http:// www.prensa.argentina.ar/2013/06/21/41810-130-mil-cooperativistas-en-el-planargentina-trabaja.php 


\section{NOTAS DE DIARIO}

Diario Clarín. Pobreza: Cristina rechazó críticas y anunció un plan de empleo. 15 de agosto de 2009. Disponible en: http://edant.clarin.com/diario/2009/08/15/elpais /p-01978818.htm

\section{PEDIDOS DE ACCESO A LA INFORMACIÓN}

Pedido de acceso a la información al Ministerio de Desarrollo Social realizado por Poder Ciudadano. 4 de noviembre de 2011.

DENISE KASPARIAN es socióloga y becaria doctoral del Consejo Nacional de Investigaciones Científicas y Técnicas con sede en el Instituto de Investigaciones Gino Germani de la Universidad de Buenos Aires. Además es docente en la carrera de Sociología de la Universidad de Buenos Aires.

Recibido: 18/06/2014

Aceptado: 12/12/2014 